\title{
Inedible Producers in Food Webs: Controls on Stoichiometric Food Quality and Composition of Grazers
}

\author{
Spencer R. Hall, ${ }^{1, *}$ Mathew A. Leibold, ${ }^{2, \dagger}$ David A. Lytle, ${ }^{3, \neq}$ and Val H. Smith ${ }^{4, \$}$
}

1. School of Integrative Biology, University of Illinois, Urbana, Illinois 61801;

2. Section of Integrative Biology, University of Texas, Austin, Texas 78712;

3. Department of Zoology, Oregon State University, Corvallis, Oregon 97331;

4. Program in Ecology and Population Biology, Department of Ecology and Evolutionary Biology, University of Kansas, Lawrence, Kansas 66045

Submitted September 19, 2005; Accepted January 6, 2006; Electronically published March 23, 2006

Online enhancements: appendixes.

ABSTRACT: Ecological stoichiometry and food web theories focus on distinct mechanisms that shape communities. These mechanisms, however, likely interact in ways that neither theory alone addresses. To illustrate, we show how a model that tracks flow of energy and nutrients through two producers and two grazers reveals two indirect, interrelated roles for "neutrally inedible" producers. First, inedible producers can exert controls over the nutrient content of edible producers and indirectly influence whether grazers are nutrient or energy limited. Second, through these controls, inedible producers can shape community assembly by excluding grazers that are weak competitors for nutrients contained in edible producers. A mesocosm experiment revealed patterns consistent with both predictions: high abundances of inedible algae were accompanied by low phosphorus contents of edible algae and low abundances of the grazer Daphnia. Both lines of inference suggest that interactions between stoichiometry and plant heterogeneity may shape plankton communities.

Keywords: cascade competition, coexistence, ecological stoichiometry, inedibility, light : nutrient gradients, plant defense.

\footnotetext{
* Corresponding author. Present address: Department of Biology, Indiana University, 1001 East 3rd Street, Bloomington, Indiana 47405-3700; e-mail: sprhall@indiana.edu.

† E-mail: mleibold@mail.utexas.edu.

${ }^{\ddagger}$ E-mail: david.lytle@science.oregonstate.edu.

s E-mail: vsmith@ku.edu.
}

Am. Nat. 2006. Vol. 167, pp. 628-637. (c) 2006 by The University of Chicago. 0003-0147/2006/16705-41310\$15.00. All rights reserved.
Variation in both species composition of producer assemblages (producer heterogeneity) and elemental composition of producers can strongly influence herbivory and allocation of nutrients and biomass among trophic levels. From a traditional food web perspective, producer heterogeneity can stabilize producer-herbivore cycling (Kretzschmar et al. 1993; Abrams and Walters 1996; McCauley et al. 1999; Genkai-Kato and Yamamura 2000; Vos et al. 2004a), yield positive correlations between the biomass of producers and their herbivores (Leibold 1996; Leibold et al. 1997; Chase et al. 2000a; Vos et al. 2004b), and facilitate coexistence of producer and grazer species (Holt et al. 1994; Grover 1995, 1997; Leibold 1996). Many of these food web effects depend explicitly on the ecosystem's nutrient supply rate. Meanwhile, work in ecological stoichiometry (Sterner and Elser 2002) has developed largely independently from this traditional food web literature. Yet these stoichiometric studies have focused on similar phenomena: variation in elemental imbalances between producers and herbivores can also influence stability of producer-herbivore interactions (Andersen 1997; Loladze et al. 2000; Muller et al. 2001), partitioning of biomass among trophic levels (Urabe and Sterner 1996; Sterner et al. 1998; Hall 2004), and community composition of grazers (Urabe et al. 2002; Hall 2004; Hall et al. 2004; Loladze et al. 2004). As in traditional theory, the food web implications of variable stoichiometry depend on resource supplies to the ecosystem, especially supplies of nutrients but also of light (e.g., the light : nutrient hypothesis; Sterner et al. 1997).

Given their conceptual parallels, these two bodies of literature should be more completely synthesized into a broader, stoichiometrically explicit food web theory. Such a synthesis has roots in past work in terrestrial systems (e.g., Owen-Smith and Novellie 1982; Belovsky and Schmitz 1994; Belovsky 1997) but may prove crucial for future extension of ecostoichiometry to both terrestrial and aquatic ecosystems (Sterner and Elser 2002; Moe et al. 2005). Our goal is to begin identifying important interactions between plant defense and stoichiometric theories via a familiar example, the case of the neutrally in- 
edible producer (Phillips 1974; Kretzschmar et al. 1993; Grover 1995). Such a producer is not consumed and does not directly influence the interaction between grazers and edible producers (i.e., no interference; Grover 1995). While not all food webs are structured by such extreme differences in edibility, this case may nonetheless apply to some of their components. For instance, filamentous algal taxa such as Oedogonium are too large to be consumed by planktonic grazers (Prescott 1982; Reynolds 1984; Sterner 1989 ) and often form large mats in ponds and experimental mesocosms (S. R. Hall, M. A. Leibold, D. A. Lytle, and V. H. Smith, unpublished data). Furthermore, the pattern of biomass partitioning in lakes with nutrient enrichment (i.e., increases in inedible but not in edible producers; Watson and McCauley 1988; Watson et al. 1992) closely resembles predictions from models with neutrally inedible producers (Phillips 1974; Grover 1995). Such patterns also arise in models with intraspecific heterogeneity of defense (Vos et al. 2004b), but the neutrally inedible case provides a relevant, simple, and tractable starting point.

Inspired by this familiar example, we used a model to show how neutrally inedible producers can alter stoichiometry-mediated food web structure and interactions among species. First, inedible producers can influence the cellular nutrient content of edible producers. Through this indirect pathway, inedible producers can then shape the community structure of grazers via "cascade competition" (a phenomenon in which taxa in different trophic levels compete indirectly with each other; Grover 1997). We derived these predictions by adding an inedible producer to a stoichiometrically explicit model of competition among grazers for an edible producer (Hall 2004). This model tracks flow of energy (carbon) and a nutrient through the four species across gradients of nutrient and light supply. We then compared predictions from this model with results from a mesocosm experiment with diverse assemblages of producers and grazers (Hall et al. 2004, 2005). Although not designed to formally test the model, the experiment did yield the signature of the model's two main predictions. Combined, the model and the data suggest that interactions between ecostoichiometry and heterogeneity of producers may play a role in structuring natural communities of pond plankton.

\section{Model}

The Lotka-Volterra-like food web model consists of an edible and an inedible producer $\left(A_{\mathrm{E}}\right.$ and $A_{\mathrm{I}}$, respectively), up to two grazers $\left(G_{1}\right.$ and $\left.G_{2}\right)$, and a nutrient resource $(R)$. This model is a variation on that of Hall (2004), which in turn is related to other stoichiometrically explicit food chain and web models (Andersen 1997; Loladze et al. 2000,
2004; Muller et al. 2001). Using ordinary differential equations, the model represents growth rates as the balance between gains and losses (for details, see app. A and tables $\mathrm{A} 1$ and $\mathrm{A} 2$ in the online edition of the American Naturalist):

$$
\begin{aligned}
& \frac{d A_{\mathrm{E}}}{d t}=u_{\mathrm{E}}\left(1-\frac{k_{\mathrm{Q}}}{Q}\right)\left(\frac{L}{b+L}\right) A_{\mathrm{E}}-m_{\mathrm{E}} A_{\mathrm{E}}-A_{\mathrm{E}} \sum_{j} f_{j} G_{j}, \\
& \frac{d Q}{d t}=v R-u_{\mathrm{E}}\left(1-\frac{k_{\mathrm{Q}}}{Q}\right) \frac{L}{b+L} Q, \\
& \frac{d G_{j}}{d t}=\min \left(e_{\mathrm{C}, j} f_{j} A_{\mathrm{E}}-r_{j}, e_{\mathrm{R}, j} f_{j} A_{\mathrm{E}} \frac{Q}{q_{\mathrm{G}, j}}\right) G_{j}-d_{j} G_{j}, \\
& \frac{d A_{\mathrm{I}}}{d t}=u_{\mathrm{I}} R\left(\frac{L}{L+b_{\mathrm{I}}}\right)-m_{\mathrm{I}} A_{\mathrm{I}}, \\
& R=S-Q A_{\mathrm{E}}-\sum_{j} q_{\mathrm{G}, j} G_{j}-q_{\mathrm{I}} A_{\mathrm{I}},
\end{aligned}
$$

where $j=1,2$. The growth rate of the edible producer, $A_{\mathrm{E}}$ (eq. [1a]), is the balance between gains from production and losses due to herbivory by grazers $G_{j}$ (which feed at rate $f_{j}$, according to a linear functional response) and other, density-independent causes $\left(m_{\mathrm{E}}\right)$. Per capita production, in turn, is a multiplicative function (Huisman and Weissing 1995) of maximal growth rate $\left(u_{\mathrm{E}}\right)$, nutrient : carbon content of the edible producer $Q$ (following the standard variable-stores-Droop formulation [Droop 1968; Grover 1997], where $k_{\mathrm{Q}}$ is the minimal nutrient quota), and light $L$. This dependence on light follows the Monod model, where $b$ is the half-saturation constant. At first, we assume no extinction of light with depth for simplicity, but later we include vertical light extinction (Huisman and Weissing 1995); see appendix B in the online edition of the American Naturalist. The nutrient : carbon quota of the producer (eq. $[1 \mathrm{~b}]), Q$, is represented dynamically. Dynamics of quota $Q$ reflect the net result of cellular gains from linear uptake of freely available nutrients, $R$ (at uptake rate $v$ ), and cellular losses due to "dilution by growth" (Grover 1997).

Grazer growth rate (eq. [1c]) is the balance between feeding gains and losses due to death (at rate $d_{j}$ ). The efficiency at which grazers convert edible food into new tissue depends on the imbalance between the nutrient : carbon contents of the edible producer $(Q)$ and the grazer $\left(q_{\mathrm{G}, j}\right)$. It also depends on feeding rate $\left(f_{j}\right)$ on edible producers $\left(A_{\mathrm{E}}\right)$, respiration rate (at rate $r_{j}$ ), and the grazer's maximal conversion efficiency for carbon $\left(e_{\mathrm{C}, j}\right)$ and nutrient $\left(e_{\mathrm{R}, j}\right)$ contained in their food. Grazing is nutrient limited when 


$$
Q<q_{\mathrm{G}, j}\left(\frac{e_{\mathrm{C}, j}}{e_{\mathrm{R}, j}}-\frac{r_{j}}{e_{\mathrm{R}, j} f_{j} A_{\mathrm{E}}}\right)
$$

and carbon limited otherwise (as governed by the minimum function $\min (\ldots)$ in eq. [1c]).

Growth rate of the inedible producer, $A_{\mathrm{I}}$ (eq. [1d]), follows the balance of losses (at rate $m_{\mathrm{I}}$ ) and gains from production from a multiplicative function of light $(L$, where $b_{\mathrm{I}}$ is the half-saturation constant) and available nutrients $R$. Nutrient uptake follows linear kinetics (at rate $u_{1}$ ), assuming that the nutrient: carbon stoichiometry of the inedible producer is fixed (at $q_{\mathrm{I}}$ ). This fixed-stoichiometry assumption initially seems startling. However, as we show below (app. B), the qualitative outcomes of the model remain robust to including flexible stoichiometry of the inedible producer. Finally, nutrient dynamics (eq. [1e]) follow the mass balance constraint representation developed especially by Grover $(1995,1997)$. This algebraic equation approximates closed systems and certain open ones (Grover 1997), and it states that all nutrients of the ecosystem $(S)$ not contained in biomass of edible producers $\left(Q A_{\mathrm{E}}\right)$, grazers $\left(\sum q_{j} G_{j}\right)$, and inedible producers $\left(q_{1} A_{1}\right)$ are available $(R)$.

This simple model reveals that inedible producers can play a significant role in shaping the allocation of equilibrial nutrient and biomass among trophic levels. This role becomes apparent with a comparison between a grazer-edible producer food chain, a food web with both grazers and the edible producer, and a food web with one grazer and both producers (fig. 1; see app. A for details). In the food chain, a grazer can invade the edible-produceronly system once it contains sufficient sequestered nutrient in edible producers $\left(Q A_{\mathrm{E}}\right)$ to meet the grazer's minimal nutrient demands $\left(Q A_{\mathrm{E}, 1}^{*}\right.$ for grazer $G_{1}$, as illustrated in fig. 1; Hall 2004). With further nutrient enrichment, the biomass of the grazer increases, while that of the edible producer decreases. This decrease occurs because the grazer's realized conversion efficiency (governed by the minimum function) increases with enrichment (Hall 2004). Once the grazer becomes carbon limited, biomass of the edible producer remains at the grazer's minimal carbon requirement $\left(A_{\mathrm{E}, 1}^{*}\right)$, while sequestered nutrient in edible producers $\left(Q A_{\mathrm{E}}^{*}\right)$ increases. Meanwhile, both nutrient quota of the edible producer $(Q)$ and freely available nutrients $(R)$ increase with nutrients, even as the grazer transitions from nutrient to carbon limitation. In addition, both quota and freely available nutrients increase if light supply $(L)$ diminishes (i.e., $\partial Q^{*} / \partial L<0$ and $\partial R^{*} / \partial L<0$ ). Thus, nutrient content of the edible producer is directly controlled by nutrient $(S)$ and light $(L)$ supply, as assumed in the light: nutrient hypothesis (Sterner et al. 1997).

Another grazer can invade this food chain. This grazer
$\left(G_{2}\right)$ can displace grazer 1 or coexist with it (as shown in Hall 2004). More specifically, if grazer 1 is a superior nutrient competitor but becomes carbon limited, a superior carbon competitor $\left(G_{2}\right)$ can invade if edible producers contain sufficient sequestered nutrient to meet its minimal nutrient demands (fig. 1). Once grazer 2 invades, biomass $\left(A_{\mathrm{E}}\right)$ and nutrient content $(Q)$ of the edible producer and nutrients sequestered in it $\left(Q A_{\mathrm{E}}\right)$ become fixed solely by traits of the two grazers (to $A_{\mathrm{E}, 1}^{*}, Q_{\mathrm{Co}}^{*}$, and $Q A_{\mathrm{C} \text {, }}^{*}$ respectively, where "Co" corresponds to grazer coexistence). Meanwhile, free nutrients become independent of nutrient supply (S) but not of light ( $L$ ) (at $R_{\mathrm{Co}}^{*}$; fig. 1). This situation persists until grazer 2 displaces its competitor with further nutrient enrichment. After this point, the grazer 2-edible producer system behaves like the food chain.

A rather different situation arises if an inedible producer $\left(A_{\mathrm{I}}\right)$ invades and persists with the edible producer and grazer 1 (fig. 1). Once the system meets the inedible producer's minimal nutrient requirement $\left(R_{\mathrm{I}}^{*}\right)$, the inedible producer can invade. After this invasion, all further nutrients supplied are shunted into inedible biomass, while grazer and edible-producer biomass remain constant (as in Phillips 1974; Grover 1995). Biomass of inedible producers does decrease as light supply $(L)$ diminishes, however (i.e., $\partial A_{I}^{*} / \partial L>0$ ). The new insight here is that light supply and inedible producers jointly control the nutrient content $(Q)$ of edible producers. Light supply controls this quota via the inedible producer's light kinetics. Inedible producers also control nutrient content of edible producers by fixing the amount of freely available nutrient to the inedible producer's minimal requirement. Thus, via indirect pathways, variation in light supply yields a negative relationship between nutrient content of edible producers and biomass of inedible producers. Through this influence on stoichiometric food quality, inedible producers can indirectly determine whether a grazer is nutrient or carbon limited. Furthermore, at identical resource supply, edible producers have lower nutrient content in the presence of inedible producers (food web) than in their absence (food chain; fig. 1).

This pathway indirectly drives a second key result: at higher nutrient supply, either grazer 1 or grazer 2 wins competition between them, but both grazers cannot coexist with both producers (fig. $2 A$ ). The outcome of competition among grazers depends on the competitive ability of the inedible producer for nutrients (i.e., its minimal $\left.R_{\mathrm{I}}^{*}\right)$ relative to the available nutrients provided when the grazers coexist $\left(R_{\mathrm{Co}}^{*} ;\right.$ fig. $\left.2 B\right)$. If the inedible producer is a weak competitor $\left(R_{\mathrm{I}}^{*}>R_{\mathrm{Co}_{0}}^{*}\right)$, the inedible producer persists with grazer 2 (the superior carbon competitor) at high enrichment-but only after grazer 2 competitively excludes grazer 1 (the superior nutrient competitor; fig. $2 A$ ). While the grazers coexist, they prevent the inedible pro- 


\section{$A_{E}-G_{1}$ chain $\quad A_{E}-G_{1}-G_{2}$ web $A_{E}-G_{1}-A_{1}$ web}

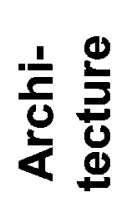

(G)

$A_{E}$

(R)

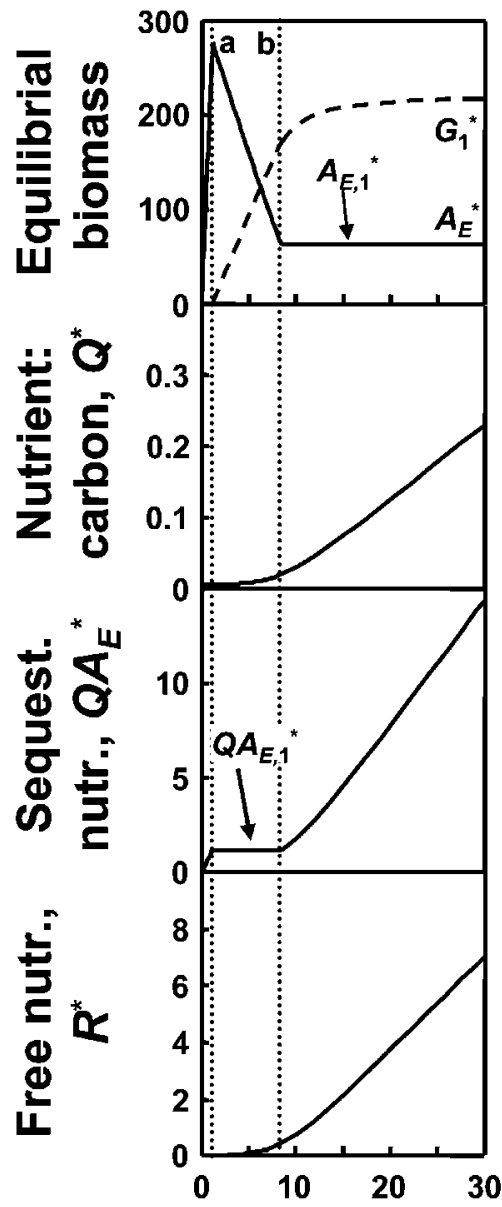

(G) $G_{3}$

(A)

(R)

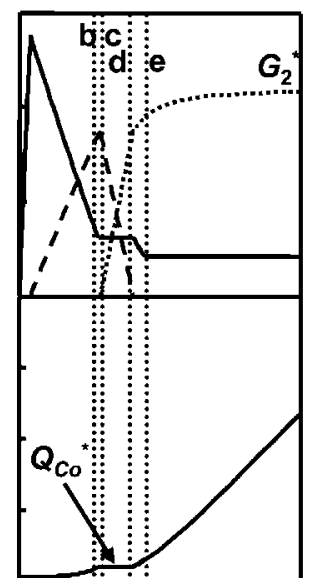

:

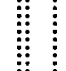

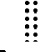

$Q A_{E, C O}$
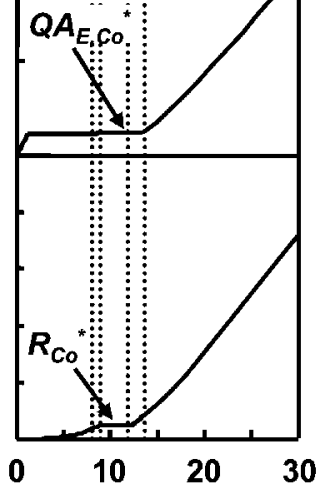

G

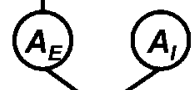

(R)

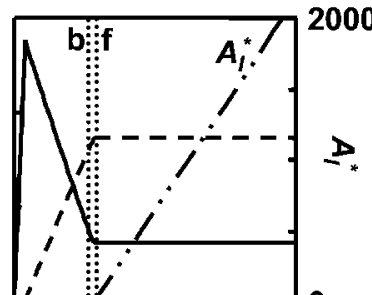

0

\section{Nutrient supply, $S$}

Figure 1: Partitioning of biomass and nutrients among compartments of a food chain with an edible producer and grazer $\left(A_{\mathrm{E}^{-}}-G_{1}\right.$; left $)$, a food web with one edible producer and two grazers $\left(A_{\mathrm{E}}-G_{1}-G_{2}\right.$; middle), and a food web consisting of the edible producer-grazer 1 food chain plus a neutrally inedible producer $\left(A_{\mathrm{I}}\right.$, right). Note that biomass of inedible producers scales along its own axis in this last case. All webs contain an available nutrient resource $(R)$. Several thresholds separate transitions along a nutrient supply $(S)$ gradient. In the food chain, once nutrient supply exceeds $a$, the system can support a nutrient-limited grazer until $b$ is passed. Afterward, the grazer becomes carbon limited. After this point, another grazer can enter and coexist past $c$, forming a web where the edible producer supports both grazers. Eventually, the first grazer (the superior nutrient competitor, $\left.G_{1}\right)$ is displaced by the superior carbon competitor $\left(G_{2}\right)$ at $d$; then grazer 2 becomes carbon limited past $e$. An inedible producer, $A_{\mathrm{I}}$, can invade the edible producer-grazer 1 food chain once $f$ is crossed. Once the inedible producer invades, all other food web and nutrient components cease to respond to enrichment. Equilibrial quantities are described in the text. 

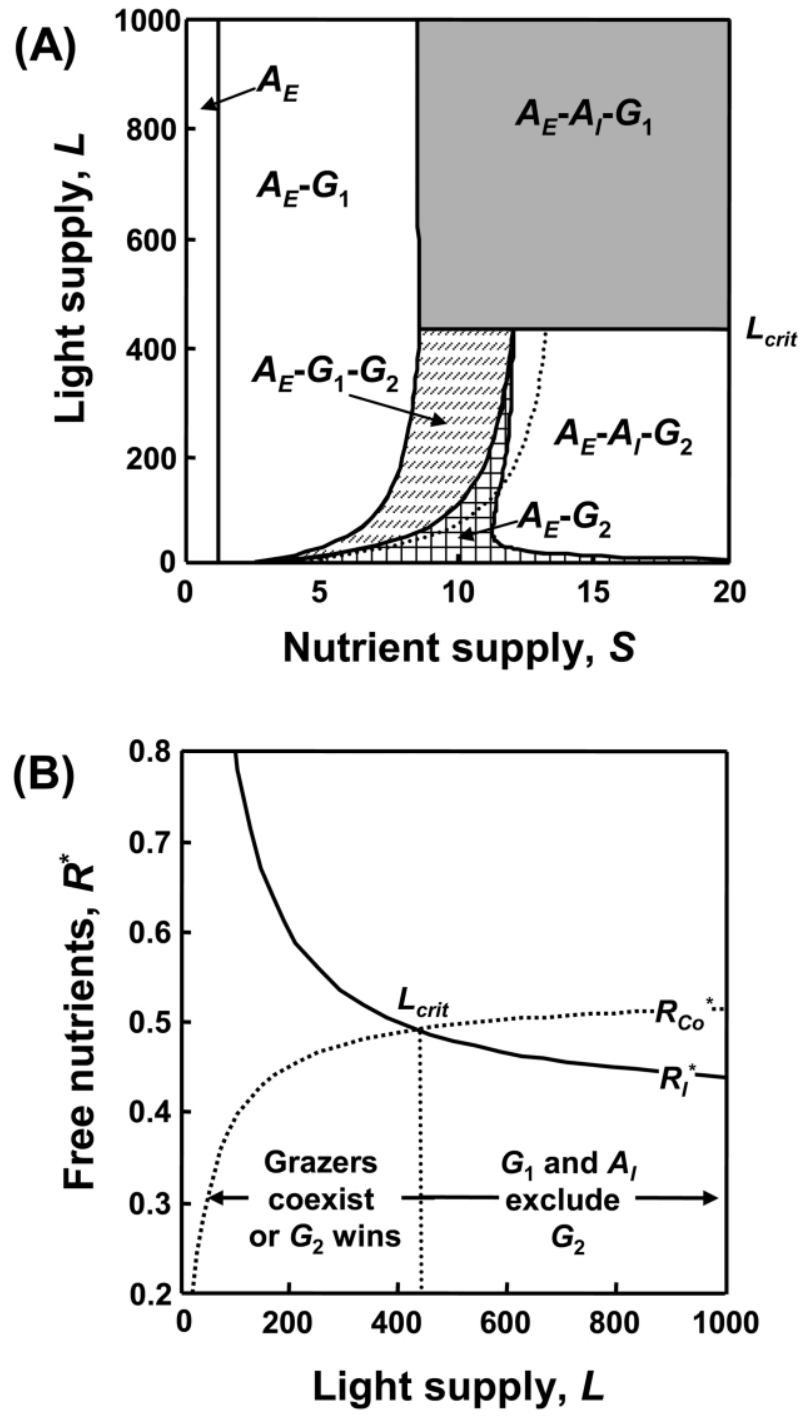

Figure 2: A, Along gradients of nutrient enrichment and light supply, two qualitative outcomes emerge in food webs with two grazers $G_{i}$, an edible producer $A_{\mathrm{E}}$, and a neutrally inedible producer $A_{\mathrm{I}}$. At low light supply (below $L_{\text {crit }}$ ), coexisting grazers can prevent the inedible producers from invading. The system transitions from dominance by the superior nutrient competitor $\left(G_{1}\right)$ to coexistence of this grazer with the superior carbon competitor $\left(G_{2}\right)$ to exclusion of grazer 1. Once grazer 2 excludes grazer 1, the inedible producer invades and persists with grazer 2, regardless of whether nutrients limit this grazer (left of dotted curve) or carbon does (right of dotted curve). At higher light supply, the inedible producer invades the edible producer-grazer 1 system and prevents invasion by grazer 2 . At high levels of enrichment, either grazer 1 (high light) or grazer 2 (low light) persists with the inedible producer. $B$, These two outcomes are driven by the availability of nutrients. Below $L_{\text {crit }}$, the minimal nutrient demands of the inedible producer $\left(R_{\mathrm{I}}^{*}\right)$ exceed that supplied by the $A_{\mathrm{E}}-G_{1}-G_{2}$ system $\left(R_{\mathrm{Co}}^{*}\right)$; thus, the inedible producer cannot invade and persist when grazers coexist. Above $L_{\text {crit }}$ however, this ranking reverses, and inedible producers indirectly prevent coexistence of grazers. ducer from invading via cascade competition. Once grazer 2 excludes grazer 1 , available nutrient eventually surpasses the minimal requirement of the inedible producer with further enrichment. If the inedible producer is a superior competitor $\left(R_{\mathrm{I}}^{*}<R_{\mathrm{Co}}^{*}\right)$, it keeps sequestered nutrient in edible producers so low $\left(Q A_{\mathrm{E}, \mathrm{I}}^{*}<\mathrm{Q} A_{\mathrm{E}, 2}^{*}\right)$ that it prevents grazer 2 , the inferior nutrient competitor, from ever invading (again, via cascade competition; fig. $2 A$ ). The outcome depends on external light supply $(L)$. Specifically, when light supply is higher than a key level $\left(L_{\text {crit }}\right)$, the inedible producer can prevent invasion by the superior carbon competitor (because then $R_{\mathrm{I}}^{*}<R_{\mathrm{Co}}^{*}$; fig. $2 B$ ).

These two main results hold when nutrient content of inedible producers changes dynamically, but they become slightly modified if light extinction is coupled with this variable quota (see app. B for details). In the situation without light extinction, nutrient content of inedible producers remains at its realized minimum $\left(Q_{I}^{*}\right)$, insensitive to nutrient supply but responding negatively to light supply. Available nutrients $\left(R^{*}\right)$ are still set by this trait $\left(Q_{\mathrm{I}}^{*}\right)$ and other traits of the inedible producer. Thus, inedible producers still exert control over nutrient content of edible producers and mediate interactions among grazers through cascade competition. When light supply becomes a function of depth, coexistence of both grazers and both producers becomes possible at intermediate light supply (fig. B1 in the online edition of the American Naturalist). This situation becomes possible because inedible producers no longer completely control freely available nutrient $(R)$ and nutrient contained (quota, $Q$, and sequestered, $\mathrm{Q} A_{\mathrm{E}}$ ) in edible producers (fig. B1). This loss of control occurs as inedible producers shade themselves. However, despite this possibility of coexistence among the four species, this model variant still predicts strong influence of inedible producers over composition of grazer assemblages through indirect, stoichiometric pathways. Specifically, the superior nutrient competitor (grazer 1) should dominate at high light, while the superior carbon competitor (grazer 2) should dominate at low light. In both cases, the winning grazer coexists with the inedible producer (fig. B1).

Consequently, the model (and its variants in app. B) makes two predictions. First, inedible producers can partially control nutrient content of edible producers (prediction 1). This control works through resource supply itself and through traits of the producers. Variation in light supply should yield a negative relationship between inedible biomass and nutrient content of edible producers. Furthermore, at given resource supply, edible producers should have higher nutrient content in systems without inedible producers than in those with them. Second, via cascade competition, inedible producers can exclude grazers that are superior carbon competitors but inferior nu- 
trient competitors (prediction 2), particularly at high irradiance.

\section{Experiment}

We explored these predictions using results from an outdoor pond mesocosm experiment. Details of the experiment are presented elsewhere (app. C in the online edition of the American Naturalist; also Hall et al. 2004, 2005) and are briefly summarized here. We factorially manipulated light and nutrient supply and trophic structure in $300-\mathrm{L}$ cattle tank mesocosms during the summer of 2000. During May-June, we created and then maintained nutrient supply gradients using inorganic nitrogen $(\mathrm{N})$ and phosphorus $(\mathrm{P})$ at two levels (low and high $[10 \times$ low]; nutrient supply level treatment) and at three different ratios $(\mathrm{N}: \mathrm{P}$ by mass $=50: 1,14: 1$, and $5: 1 ; \mathrm{N}: \mathrm{P}$, or nutrient ratio, treatment). We added nutrients weekly to maintain target levels created by these treatments (total $\mathrm{N}$ and total P levels of 700 and 14, 370.4 and 26.5, and 221.4 and $44.3 \mu \mathrm{g} \mathrm{L}{ }^{-1}$, respectively, in the low-nutrient-supplylevel treatment). The nutrient ratio treatment did not drive the patterns shown below, but the data from all $\mathrm{N}: \mathrm{P}$ treatments are included. We also manipulated light (light treatment), using $90 \%$ shade cloth. We inoculated each mesocosm with diverse assemblages of algae and zooplankton fortnightly.

We sampled the experiment after 90 days to characterize response of biomass and stoichiometry of algae and zooplankton community structure. This period of time is sufficient to eliminate transient dynamics in our experiments (Leibold et al. 2005). We split algal samples into "edible" $(<35 \mu \mathrm{m})$ and "inedible" $(>35 \mu \mathrm{m})$ size fractions (Cottingham 1999). While this fractionation could include some large edible (and maybe somewhat resistant) algae in the inedible class, this category mainly consisted of large, neutrally inedible, filamentous algae (especially Oedogonium). We estimated biomass (chlorophyll $a$ ) of both fractions with fluorometry. In addition, we characterized the stoichiometry of the edible fraction with a CHN autoanalyzer and spectrophotometry. Finally, we identified and estimated biomass of preserved zooplankton, using a dissecting microscope.

In this experiment, inedible producers responded to the light and nutrient supply. As predicted by the models, inedible producers were more abundant at full light than in shade when nutrient supply was high; however, little difference was detected at low nutrient supply (nutrient supply $\times$ light interaction, $P=.028$; table $\mathrm{C} 1$ in the online edition of the American Naturalist; fig. 3A). Meanwhile, edible biomass increased with resource supply, although responses to both treatments were marginally significant (nutrient supply effect, $P=.079$; light effect,
$P=.083$; table $\mathrm{C} 1)$. The nutrient effect was not predicted by any of the models examined here, but the positive light effect was anticipated, especially by the variant with light extinction (see app. B). At high nutrient supply, the light effect on inedible biomass drove a negative relationship between $\log$ (biomass of inedible algae) and $\log$ (phosphorus quota of edible algae; fig. 3C). Phosphorus quota did decrease with increasing light (Hall et al. 2004), as predicted here. However, light did not completely drive this quota-inedible biomass relationship, because it emerged after controlling for both $\mathrm{N}: \mathrm{P}$ and light supply treatments (partial regression slope [95\% confidence intervals (CIs)] of $-0.13[-0.39,-0.09]$; partial weighted sum of squares of errors $[\mathrm{SSE}]=3.12 ; P=.002)$. No such relationship arose at low supply of nutrients.

At high nutrient supply, this phosphorus quota-inedible producer relationship then corresponded to abundance of Daphnia in two ways. First, the proportion of crustacean zooplankton biomass composed of Daphnia (arcsinesquare root transformed) increased significantly with $\log$ (phosphorus quota of edible algal species) (fig. $3 D$; partial slope $[95 \% \mathrm{CIs}]=1.37 \quad[0.71,1.75]$; partial weighted SSE $=29.7 ; P=.030$ ). The models here forecast this result-if Daphnia acted as the superior carbon competitor. Second, a threshold level of inedible algal biomass (found using tree regression) separated regions where Daphnia could dominate grazer assemblages (low inedible biomass) from those in which Daphnia were rarer (high inedible biomass; fig. $3 E$ ). Such a pattern occurs in the models as inedible producers indirectly push out the superior carbon competitor. Thus, Daphnia were rarer in systems that had both more inedible algae and lower nutrient content of edible algae. Daphnia were very uncommon at low nutrient enrichment, regardless of light supply (shown in Hall et al. 2004).

\section{Discussion}

Our results revealed a new ecological role for producer defenses to play in food webs. Producers using an extreme type of defense, neutral inedibility, can shape grazer communities through two indirect yet interrelated pathways. First, these producers can indirectly influence nutrient content of edible producers (prediction 1). This influence occurs through the inedible producers' partial control of nutrients available for uptake and through their influence on light supply (shading). Consistent with this prediction, we found a negative relationship between phosphorus content of smaller, edible algae and biomass of larger, inedible algae in the high-nutrient-supply treatment of a pond mesocosm experiment. This indirect pathway is important because it might determine nutrient or carbon limitation 
(A)

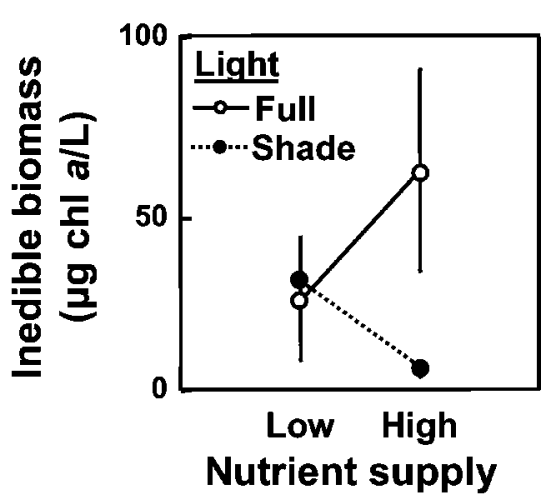

(C)

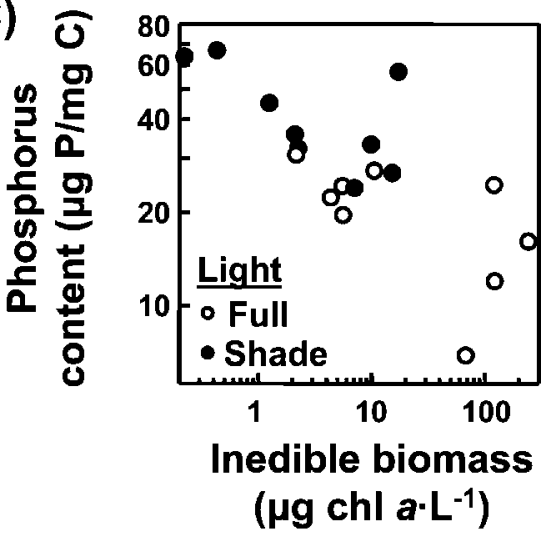

(B)

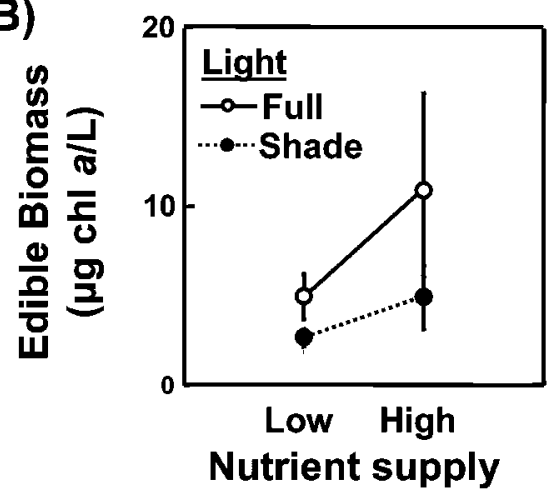

(D)

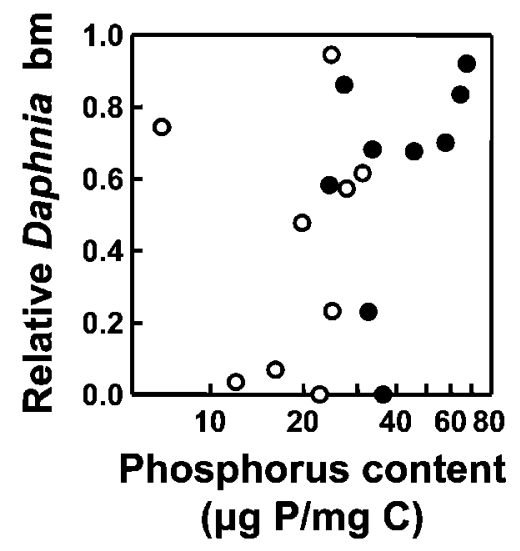

(E)

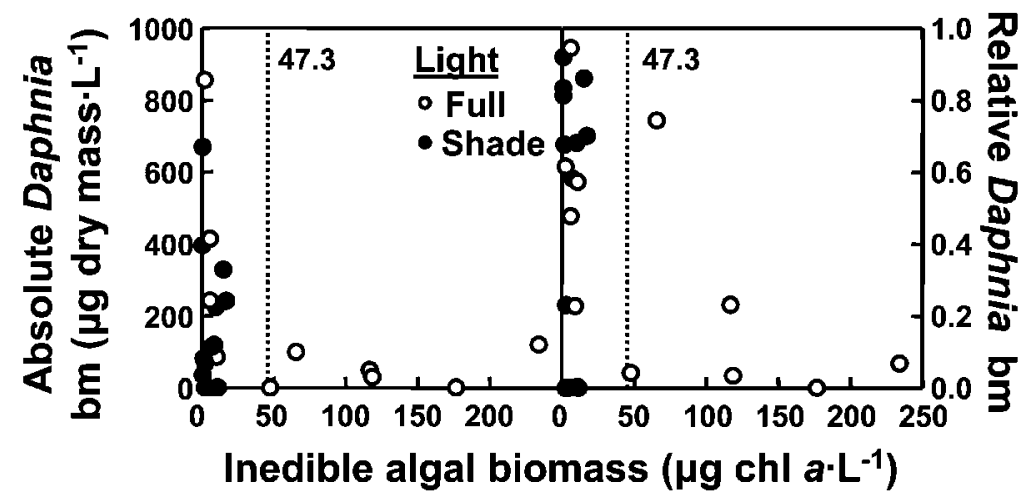

Figure 3: Results from a mesocosm experiment were consistent with several model predictions. $A$, High inedible-producer biomass was achieved at full light in highly enriched conditions, yet inedible-producer biomass remained low in shaded but enriched conditions. $B$, Meanwhile, edible biomass responded weakly to the light-nutrient gradient. $C$, The light-inedible biomass effect at high nutrient supply drove a negative correlation between phosphorus content of edible algae and biomass of inedible algae (but not at low nutrient supply; not shown). In high-nutrient systems, relative daphniid biomass positively correlated to increasing phosphorus content of edible algae $(D)$, and establishment of large blooms of inedible algae (at full light) typically corresponded with low absolute and relative biomass of Daphnia in the zooplankton assemblage (E). Yet Daphnia often dominated in systems with low amounts of inedible biomass (i.e., systems not exceeding a threshold of approximately $50 \mu \mathrm{g}$ chlorophyll $a \mathrm{~L}^{-1}$, as determined by tree regression). 
of grazers, a key aspect of ecostoichiometry (Sterner and Elser 2002).

In theory, this first mechanism can further shape community structure of grazers through "cascade competition" (sensu Grover 1997; prediction 2). In another major example of cascade competition, inedible producers displace predators of grazers in tritrophic food chains (Grover 1997). In that example, the intertrophic competitive effect is mediated jointly through resource availability and trophic interactions cascading down from the predator to the edible producer. In our example here, cascade competition occurs within two trophic levels, because inedible producers can prohibit stoichiometry-mediated coexistence of two grazers (Hall 2004; Loladze et al. 2004). Specifically, inferior nutrient competitors can be indirectly outcompeted by inedible producers because the latter depress nutrients sequestered in food below the grazer's minimal requirements. This effect should appear in more fully lighted systems; at intermediate light supply, coexistence of both grazers with both producers becomes possible when light attenuates with depth.

This second prediction (prediction 2) was echoed by results from our mesocosm experiment. It revealed a threshold level of inedible-producer biomass that, once exceeded, was associated with both lower nutrient content of edible producers and low abundance of the zooplankton grazer Daphnia. Furthermore, abundance of Daphnia related positively to phosphorus content of edible algae. Previously, this grazer was shown to be sensitive to this phosphorus content; specifically, Daphnia dominated only assemblages in environments that produced sufficiently phosphorus-rich edible producers (Hall et al. 2004). Hence, Daphnia behaved as if it were a superior carbon competitor but an inferior nutrient competitor (Hall 2004; Hall et al. 2004). In theory, such competitive status makes Daphnia vulnerable to exclusion by inedible producers and superior nutrient competitors. Thus, through an indirect pathway involving stoichiometric food quality, inedible producers may have shaped Daphnia's dominance in these grazer assemblages (although a firmer conclusion awaits more definitive tests).

These proposed stoichiometric links between Daphnia and inedible producers could have important implications for aquatic systems and lake management (McQueen 1990), but they must be teased apart in future empirical and theoretical research. Contrary to typical predictions of food web theory (Kretzschmar et al. 1993; Grover 1997), observers often document blooms of large, resistant species when Daphnia are rare, while smaller, edible species bloom when Daphnia dominate (Sterner 1989; Carpenter and Kitchell 1993; Sarnelle 1993; Nicholls et al. 1996; reviewed by Agrawal [1998]). This contradictory pattern emerged here via stoichiometry-mediated cascade competition-if
Daphnia is indeed a superior carbon competitor but an inferior nutrient competitor. Although plausible, this recently proposed aspect of Daphnia's biology (Hall 2004; Hall et al. 2004) has yet to be confirmed experimentally. Furthermore, it remains unknown whether the cascade competition result would still emerge in a more realistic model with saturating functional responses of the grazers like Daphnia. Such fully stoichiometric food web models may exhibit more complex behavior (Andersen 1997; Loladze et al. 2000; Muller et al. 2001) than typically seen in structurally equivalent food web models (Kretzschmar et al. 1993; Abrams and Walters 1996; Abrams 1999; Vos et al. 2004a).

Despite these caveats, the results reported here encourage a broader synthesis of models containing ecostoichiometry and defenses from herbivory. Hopefully, ecostoichiometry will embrace various defenses seen in planktonic systems (Arnold 1971; Porter and Orcutt 1980; Porter 1976; Lampert 1987; DeMott and Tessier 2002; Vos et al. 2004a, 2004b) as factors driving elemental imbalances between producers and grazers. More generally, these findings push for more complete integration of food web and stoichiometric models designed for various ecosystems (Moe et al. 2005). In other ecosystems, stoichiometric imbalances between producers and herbivores appear to be large (Elser et al. 2000; Sterner and Elser 2002). However, these imbalances also coincide with variation in producer defense (Coley and Aide 1991; Grover 1995; Coley and Barone 1996; Chase et al. 2000a, 2000b), which can be induced (Havel 1987; Abrams and Walters 1996; Tollrian and Harvell 1999; Vos et al. 2004a, 2004b) and can rapidly evolve (Shertzer et al. 2002; Yoshida et al. 2003). It seems likely that stoichiometric mechanisms interact with defenses to shape food web assembly and dynamics in other systems as well.

\section{Acknowledgments}

We thank T. Darcy-Hall, A. Downing, P. Geddes, and N. Howe for help with sampling and T. Darcy-Hall, G. Mittelbach, and two anonymous reviewers for commenting on the manuscript. We analyzed the $\mathrm{C}: \mathrm{N}$ samples in the Robertson lab at the W. K. Kellogg Biological Station (KBS) with the help of A. Corbin and T. Darcy-Hall. Thanks also go to N. Consolatti, G. Mittelbach, A. Tessier, and P. Woodruff for technical support. Primary funding came from National Science Foundation (NSF) grant DEB 98-15799. S.R.H. was supported by an NSF graduate fellowship, a University of Chicago Harper Fellowship and Hinds Fund award, a Graduate Assistance in Areas of National Need training grant, and an NSF Doctoral Dissertation Improvement Grant (DEB 01-05014). This is KBS contribution 1209 . 


\section{Literature Cited}

$\rightarrow$ Abrams, P. A. 1999. Is predator-mediated coexistence possible in unstable systems? Ecology 80:608-621.

Abrams, P. A., and C. J. Walters. 1996. Invulnerable prey and the paradox of enrichment. Ecology 77:1124-1133.

$\rightarrow$ Agrawal, A. A. 1998. Algal defense, grazers, and their interactions in aquatic trophic cascades. Acta Oecologica 19:331-337.

Andersen, T. 1997. Pelagic nutrient cycles: herbivores as sources anisinks. Springer, New York.

$\rightarrow$ Arnold, D. E. 1971. Ingestion, assimilation, survival, and reproduction of Daphnia pulex fed seven species of blue-green algae. Lim nology and Oceanography 16:906-920.

$\rightarrow$ Belovsky, G. E. 1997. Optimal foraging and community structure: the allometry of herbivore food selection and competition. Evo lutionary Ecology 11:641-672.

$\rightarrow$ Belovsky, G. E., and O. J. Schmitz. 1994. Plant defenses and optimal foraging by mammalian herbivores. Journal of Mammology 75 816-832.

Carpenter, S. R., and J. F. Kitchell, eds. 1993. The trophic cascade in lakes. Cambridge University Press, New York.

$\rightarrow$ Chase, J. M., M. A. Leibold, A. L. Downing, and J. B. Shurin. $2000 a$. The effects of productivity, herbivory, and plant species turnover in grassland food webs. Ecology 81:2485-2497.

$\rightarrow$ Chase, J. M., M. A. Leibold, and E. Simms. 2000b. Plant tolerance and resistance in food webs: community-level predictions and evolutionary implications. Evolutionary Ecology 14:289-314.

Coley, P. D., and T. M. Aide. 1991. Comparison of herbivory and plant defenses in temperate and tropical broad-leaved forests. Pages 25-49 in P. W. Price, T. M. Lewinsohn, G. W. Fernandes, and W. W. Benson, eds. Plant-animal interactions: evolutionary ecology in tropical and temperate regions. Wiley, New York.

$\rightarrow$ Coley, P. D., and J. A. Barone. 1996. Herbivory and plant defensec in tropical forests. Annual Review of Ecology and Systematics 27: 305-335.

$\rightarrow$ Cottingham, K. L. 1999. Nutrients and zooplankton as multiple stressors of phytoplankton communities: evidence from size structure. Limnology and Oceanography 44:810-827.

$\rightarrow$ DeMott, W. R., and A. J. Tessier. 2002. Stoichiometric constraints versus algal defenses: testing mechanisms of zooplankton food limitation. Ecology 83:3426-3433.

$\rightarrow$ Droop, M. R. 1968. Vitamin $B_{12}$ and marine ecology. IV. The kinetics of uptake, growth, and inhibition in Monochrysis lutheri. Journal of the Marine Biological Association of the United Kingdom 48: 689-733.

$\rightarrow$ Elser, J. J., W. F. Fagan, R. F. Denno, D. R. Dobberfuhl, A. Folarin. A. Huberty, S. Interlandi, et al. 2000. Nutritional constraints iı terrestrial and freshwater food webs. Nature 408:578-580.

$\rightarrow$ Genkai-Kato, M., and N. Yamamura. 2000. Profitability of prey determines the response of population abundances to enrichment. Proceedings of the Royal Society of London B 267:2397-2401.

$\rightarrow$ Grover, J. P. 1995. Competition, herbivory, and enrichment: nutrientbased models for edible and inedible plants. American Naturalis 145:746-774.

$\rightarrow$ Hall, S. R. 2004. Stoichiometrically explicit competition betweer. grazers: species replacement, coexistence, and priority effects along resource supply gradients. American Naturalist 164:157-172.

$\rightarrow$ Hall, S. R., M. A. Leibold, D. A. Lytle, and V. H. Smith. 2004. Stoi- chiometry and planktonic grazer composition over gradients of light, nutrients, and predation risk. Ecology 85:2291-2301.

Hall, S. R., V. H. Smith, D. A. Lytle, and M. A. Leibold. 2005. Constraints on primary producer $\mathrm{N}: \mathrm{P}$ stoichiometry along $\mathrm{N}: \mathrm{P}$ supply ratio gradients. Ecology 86:1894-1904.

Havel, J. E. 1987. Predator-induced defenses: a review. Pages 263278 in W. C. Kerfoot and A. Sih, eds. Predation: direct and indirect impacts on aquatic communities. University Press of New England, Hanover, NH.

Holt, R. D., J. Grover, and D. Tilman. 1994. Simple rules for interspecific dominance in systems with exploitative and apparent competition. American Naturalist 144:741-771.

Huisman, J., and F. J. Weissing. 1995. Competition for nutrients and light in a mixed water column: a theoretical analysis. American Naturalist 146:536-564.

$\rightarrow$ Kretzschmar, M. K., R. M. Nisbet, and E. McCauley. 1993. A predator-prey model for zooplankton grazing on competing algal populations. Theoretical Population Biology 44:32-66.

Lampert, W. 1987. Laboratory studies on zooplankton-cyanobacteria interactions. New Zealand Journal of Marine and Freshwater Research 21:483-490.

$\rightarrow$ Leibold, M. A. 1996. A graphical model of keystone predation: effects of productivity on abundance, incidence, and ecological diversity in communities. American Naturalist 147:784-812.

$\rightarrow$ Leibold, M. A., J. M. Chase, J. B. Shurin, and A. L. Downing. 1997. Species turnover and the regulation of trophic structure. Annual Review of Ecology and Systematics 28:467-494.

Leibold, M. A., S. R. Hall, and O. Bjørnstad. 2005. Food web architecture and its effects on consumer resource oscillations in experimental pond ecosystems. Pages 37-47 in P. C. de Ruiter, V. Wolters, and J. C. Moore, eds. Dynamic food webs: multispecies assemblages, ecosystem development, and environmental change. Academic Press, Burlington, MA.

Loladze, I., Y. Kuang, and J. J. Elser. 2000. Stoichiometry in producergrazer systems: linking energy flow with element cycling. Bulletin of Mathematical Biology 62:1137-1162.

Loladze, I., Y. Kuang, J. J. Elser, and W. F. Fagan. 2004. Coexistence of two predators on one prey mediated by stoichiometry. Theoretical Population Biology 65:1-15.

MathWorks. 1999. Matlab 5.3: the language of technical computing. MathWorks, Natick, MA.

$\rightarrow$ McCauley, E., R. M. Nisbet, W. W. Murdoch, A. M. de Roos, and W. S. C. Gurney. 1999. Large-amplitude cycles of Daphnia and its algal prey in enriched environments. Nature 402:653-656.

McQueen, D. J. 1990. Manipulating lake community structure: where do we go from here? Freshwater Biology 23:613-620.

Moe, S. J., R. S. Stelzer, M. R. Forman, W. S. Harpole, T. Daufresne, and T. Yoshida. 2005. Recent advances in ecological stoichiometry: insights for population and community ecology. Oikos 109:29-39.

Muller, E. B., R. M. Nisbet, S. A. L. M. Kooijman, J. J. Elser, and E. McCauley. 2001. Stoichiometric food quality and herbivore dynamics. Ecology Letters 4:519-529.

$\rightarrow$ Nicholls, K. H., M. F. P. Michalski, and W. Gibson. 1996. An experimental demonstration of trophic interactions affecting water quality of Rice Lake, Ontario (Canada). Hydrobiologia 319:73-85.

Owen-Smith, N., and P. Novellie. 1982. What should a clever ungulate eat? American Naturalist 119:151-178.

Phillips, O. M. 1974. The equilibrium and stability of simple marine systems. II. Herbivores. Archiv für Hydrobiologie 73:310-333. 
$\rightarrow$ Porter, K. G. 1976. Enhancement of algal growth and productivity by grazing zooplankton. Science 192:1332-1334.

Porter, K. G., and J. D. Orcutt Jr. 1980. Nutritional adequacy, man ageability, and toxicity as factors that determine the food quality of green and blue-green algae for Daphnia. Pages 268-281 in W. C. Kerfoot, ed. The evolution and ecology of zooplankton com munities. University Press of New England, Hanover, NH.

Prescott, G. W. 1982. Algae of the western Great Lakes area. Otto Koeltz Science, Koenigstein.

Reynolds, C. S. 1984. The ecology of freshwater phytoplankton. Cam bridge University Press, Cambridge.

$\rightarrow$ Sarnelle, O. 1993. Herbivore effects on phytoplankton succession in a eutrophic lake. Ecological Monographs 63:129-149.

$\rightarrow$ Shertzer, K. W., S. P. Ellner, G. F. Fussman, and N. G. Hairston Jr. 2002. Predator-prey cycles in an aquatic microcosm: testing hypotheses of mechanism. Journal of Animal Ecology 71:802-816.

Sterner, R. W. 1989. The role of grazers in phytoplankton succession. Pages 107-170 in U. Sommer, ed. Phytoplankton ecology: succession in plankton communities. Springer, Berlin.

Sterner, R. W., and J. J. Elser. 2002. Ecological stoichiometry: the biology of elements from molecules to the biosphere. Princeton University Press, Princeton, NJ.

$\rightarrow$ Sterner, R. W., J. J. Elser, E. J. Fee, S. J. Guilford, and T. H. Chrzanowski. 1997. The light : nutrient relation in lakes: the balance of energy and materials affects ecosystem structure and process. American Naturalist 150:663-684.

$\rightarrow$ Sterner, R. W., J. Clausen, W. Lampert, and T. Weisse. 1998. Carbon : phosphorus stoichiometry and food chain production. Ecology Letters 1:146-150.
Tollrian, R., and C. D. Harvell. 1999. The ecology and evolution of inducible defenses. Princeton University Press, Princeton, NJ.

Urabe, J., and R. W. Sterner. 1996. Regulation of herbivore growth by the balance of light and nutrients. Proceedings of the National Academy of Sciences of the USA 93:8465-8469.

Urabe, J., M. Kyle, W. Makino, T. Yoshida, T. Andersen, and J. J. Elser. 2002. Reduced light increases herbivore production due to stoichiometric effects of light/nutrient balance. Ecology 83:619627.

$\rightarrow$ Vos, M., B. W. Kooi, D. L. DeAngelis, and W. M. Mooij. $2004 a$. Inducible defenses and the paradox of enrichment. Oikos 105: 471-480.

$\rightarrow$ Vos, M., A. M. Verschoor, B. W. Kooi, F. L. Wackers, D. L. DeAngelis, and W. M. Mooij. 2004b. Inducible defenses and trophic structure. Ecology 85:2783-2794.

$\rightarrow$ Watson, S. B., and E. McCauley. 1988. Contrasting patterns of netand nannoplankton production and biomass among lakes. Canadian Journal of Fisheries and Aquatic Sciences 45:915-920.

$\rightarrow$ Watson, S. B., E. McCauley, and J. A. Downing. 1992. Sigmoid relationships between phosphorus, algal biomass, and algal community structures. Canadian Journal of Fisheries and Aquatic Sciences 49:2605-2610.

Yoshida, T., L. E. Jones, S. P. Ellner, and N. G. Hairston Jr. 2003. Rapid evolution drives ecological dynamics in a predator-prey system. Nature 424:303-306.
Associate Editor: Jef Huisman Editor: Donald L. DeAngelis 